\title{
Local Competition Between Foraging Relatives: Growth and Survival of Bruchid Beetle Larvae
}

\author{
Isabel M. Smallegange • Tom Tregenza
}

Revised: 14 February 2008 / Accepted: 22 April 2008 /

Published online: 21 May 2008

(C) Springer Science + Business Media, LLC 2008

\begin{abstract}
Kin selection theory states that when resources are limited and all else is equal, individuals will direct competition away from kin. However, when competition between relatives is completely local, as is the case in granivorous insects whose larval stages spend their lives within a single seed, this can reduce or even negate the kinselected benefits. Instead, an increase in competition may have the same detrimental effects on individuals that forage with kin as those that forage with non-kin. In a factorial experiment we assessed the effects of relatedness and competition over food on the survival and on fitness-related traits of the bruchid beetle Callosobruchus maculatus. Relatedness of competitors did not affect the survival of larvae. Larval survival substantially decreased with increasing larval density, and we found evidence that beetles maturing at a larger size were more adversely affected by competition, resulting in lower survival rates. Furthermore, females showed a reduction in their growth rate with increasing larval density, emerging smaller after the same development time. Males increased their growth rate, emerging earlier but at a similar size when food was more limited. Our results add to the growing number of studies that fail to show a relationship between relatedness and a reduction in competition between relatives in closed systems, and emphasize the importance of the scale at which competition between relatives occurs.
\end{abstract}

Keywords Density-dependent competition · Hamilton's rule · interference competition $\cdot$ life history traits $\cdot$ scale of competition

I. M. Smallegange $\cdot$ T. Tregenza

Ecology and Evolution Group, School of Biology, University of Leeds, Leeds LS2 9JT, UK

Present address:

I. M. Smallegange

Max Planck Institute for Ornithology, Vogelwarte Radolfzell, Schlossallee 2,

78315 Radolfzell, Germany

Present address:

T. Tregenza $(\bowtie)$

Centre for Ecology and Conservation, School of Biosciences, University of Exeter,

Cornwall Campus, Penryn TR10 9EZ, UK

e-mail: T.Tregenza@exeter.ac.uk 


\section{Introduction}

Competition among animals for scarce resources is a driving force in structuring populations as it has important effects on life-history strategies of individuals and the evolution of behavior (Lomnicki 1988). Much competition takes place in 'open' systems, where resources are divided into patches and individuals compete but have the choice of leaving a patch to go elsewhere. However, competition also occurs in 'closed' systems where competitors cannot leave the patch and are restricted to options about how they compete with one another. Examples of closed systems are systems where species use seasonally ephemeral habitats such as vernal ponds and tropical rain pools to breed, and where individuals typically arrive en masse to compete for receptive mates (Heyer et al. 1975; Thornhill and Alcock 1983; Newman 1987; Roberts 1994). Also, benthic colonial invertebrates, which have a sessile adult life, often face strong, inescapable competition for space and generally one competitor overgrows part or all of another (Vicente 1990; Aerts 1998). Granivorous insects, whose larval stages spend their lives within a single seed, are another example of a group of species where competition takes place in a closed system. For example, in beetles of the genus Callosobruchus, females lay eggs on the surface of various leguminous beans (Southgate 1979). On hatching, the larvae burrow into the bean where they feed and grow, after which they emerge as adults to mate and lay their eggs. As females may lay several eggs on a single bean and larvae cannot move between beans, larval competition may be intense.

Beetles of the genus Callosobruchus are stored product pests and inhabit ephemeral stores of food from which some adults disperse to colonize new stores (Imura 1990). New colonies are likely to be founded by a small number of adults, and hence subsequent generations may contain a large proportion of related individuals. Larval competition amongst relatives may therefore occur. Kin selection theory (Hamilton 1964a, b) states that when resources are limiting and all else is equal, individuals will direct competition away from kin. The inclusive fitness of an individual is its own direct fitness with the addition of any (relatedness-weighted) indirect fitness of its relatives due to actions of the focal individual (Grafen 1984). Inclusive fitness is best understood from the perspective of the likelihood of proliferation of the individual genes underlying a trait, which can increase in frequency either by making copies of themselves or by enhancing the survival and replication of copies in other individuals. When individuals share a limited resource, kin may accept a reduction in their own fitness if the costs are compensated by an increase in their inclusive fitness through an increase in fitness of their relatives. Non-kin however, will only increase their competitive efforts to acquire more resource. This original formulation of kin selection theory (Hamilton 1964a, b) has been contested because limited dispersal, which is inherent to stored product pests species, increases competition between (related) neighbors. An increase in competition may counteract the reduced level of aggression between related contestants (Queller 1994; Frank 1998) even to such an extent that the kin selection advantage in decreasing aggression and competition is reduced or even negated (West et al. 2002).

To predict the net result of increasing competition and increasing relatedness on the survival of individuals, competition between relatives has been incorporated into 
Hamilton's rule, $r b-c>0$, where $r$ is the genetic relatedness, and $b$ and $c$ express the marginal benefit and cost of increased altruism, or decreased competition (Hamilton 1964a, b). Frank (1998) has incorporated competition into Hamilton's rule by expressing $b$ as function of three parameters: $b=B-a(B-c)$, with $c$ as before and $B$ constitutes the benefit to the recipients if they do not compete with each other. The parameter $a$ is the spatial scale at which competition occurs and ranges from $a=0$ (completely global) to $a=1$ (completely local). A different method has been proposed by Queller (1994), who states that the parameter $r$ should be measured with respect to the individuals with which the beneficiary competes $\left(r_{\mathrm{c}}\right)$, rather than the global population $\left(r_{\mathrm{g}}\right)$. From both models it can be deduced (Griffin and West 2002) that the circumstances under which an individual is predicted not to direct competition away from kin are (1) when competition is extremely local [ $a=1$ (Frank 1998)], as is the case in closed systems, or (2) when the actor is equally related to the potential benefactor and to their competitors [ $r_{\mathrm{e}}=0$ (Queller 1994)].

The aim of this study is to assess the effects of relatedness and competition over food on survival and fitness-related traits in the bruchid beetle Callosobruchus maculatus. C. maculatus (Coleoptera, Bruchidae) spends the majority of its life inside a bean as a larva. Inside the bean, larvae of the 'contest type' may fight to such an extent that only one gains exclusive access to the resource and survives. In contrast, larvae of the 'scramble type' attempt to use as much of the resource as quickly as possible and usually more than one individual emerges (Toquenaga 1993; Toquenaga and Fujii 1990). Here, we use beetles of the scramble type in a laboratory experiment where we assess the effects of relatedness (full-sibs versus non-sibs) and larval density (number of larvae per bean) on larval survival. Whether or not this situation provides relatives with an opportunity to cooperate depends upon the shape of the relationship between larval resources and adult fitness. If there is a greater than linear rate of increase in adult fitness with larval resources acquired it may not pay individuals to cooperate because their total fitness will be lower when distributed evenly between them. Alternatively, if adult fitness increases with diminishing returns as larval resources increase, then related competitors may benefit by sharing resources evenly. In addition to the relationship between intake and fitness, cooperation may also be favored if scramble competition leads to lower efficiency of resource use. If cooperating larvae can use resources more efficiently (but more slowly) then we would predict that relatives will take longer to develop but emerge at higher mass. This of course assumes that larvae are able to respond to the presence of other larvae, which might be limited by the fact that larvae burrow into beans from different vantage points on the bean's surface. As a result, the distance between larvae might be too great to allow for recognition of the presence of others as well as for kin recognition. Furthermore, Mano and Toquenaga (2008) in a recent paper show that larvae of $C$. maculatus, in scramble competition, build walls inside a bean that prevent larvae from interacting directly. This again poses a physical barrier between larvae reducing the possibility for kin recognition.

Larval survival should decrease with increasing larval density regardless of the relatedness of competitors, but will be less adversely affected by density if relatives can reduce wasteful competition. It is possible that related individuals are more likely to occupy the same niche and consequently experience stronger competition than unrelated individuals in the same situation. However, the lack of strongly 
differentiated niches within a bean makes it unlikely that this is a significant effect. Furthermore, an assumption that we make is that, in order to make a choice on the intensity of direct competition, larvae should be able to discriminate between kin and non-kin. Kin recognition is speculated to be a significant factor in non-social insect interactions (Fellowes 1998). Kin recognition in C. maculatus larvae is to our knowledge unexplored. Initially, it was suggested that kin recognition might be possible as adult females were able to discriminate between eggs of kin and non-kin (Ofuya and Agele 1989). However, Messina and Tinney (1991) were unable to replicate these results and concluded that no evidence exists that kin recognition among egg-laying females occurs.

\section{Methods}

To obtain focal families, we used cultures derived from a Brazilian strain known to exhibit scramble competition that were maintained on black-eyed beans Vigna unguiculata at $29^{\circ} \mathrm{C}$. Of this strain, 28 virgin females (1-day old) were each mated to a different and unique virgin male (1-day old). Following mating, each female was allowed to oviposit on $100-110$ beans placed in a plastic pot $\left(83 \mathrm{~cm}^{3}\right)$ to obtain 28 full-sib families. The offspring of these 28 families of this second generation were used to create the full-sib and non-sib treatments of the experiment (see below). For this purpose only adult beetles that emerged from beans that contained a single larva were used. Because each of these 28 families consisted of a large number of siblings, we could use individuals of the same family to replicate treatment combinations and thereby reduce unwanted variation, for example caused by maternal effects. To this end, we created seven replicate blocks within which we used virgin beetles from four focal families and varied larval density (one, two, and four larvae per bean) and relatedness (full-sibs, non-sibs; Fig. 1). Within each block, females of each family were randomly assigned to one of the larval density treatments and mated to a male of another family (Fig. 1). After mating, each female was allowed to oviposit on adzuki beans ( $V$. angularis) placed in a $9 \mathrm{~cm}$ Petri dish; these beans were used because their small size increases the intensity of competition within a bean. Although beetles of these focal families were maintained on black-eyed beans, which are larger beans than adzuki beans, such a shift in bean size does not alter the type of competition (e.g. from scramble to contest) between larvae (Messina 2004), and hence we have no reason to expect that this host shift will alter the competitive behavior of the larvae. For the fill-sib treatments, a female of each of the four families within each block (Fig. 1) was allowed to lay eggs until at least five beans with a sufficient number of eggs for each level of larval density were available. For the non-sib treatments, the mating and egg-laying procedure for a female (of each of the four families within each block) at the lowest larval density treatment was the same as in the full-sib treatment. For the medium and high larval density treatments, respectively one and two females of each of the four families within each block were each allowed to oviposit half the required number of eggs (the order of ovipositing females was randomized; Fig. 1). When necessary, any excess eggs were scraped off using a scalpel to obtain the required number of eggs on each bean. Per treatment combination, five to ten egg-loaded beans were put separately in Eppendorf tubes 


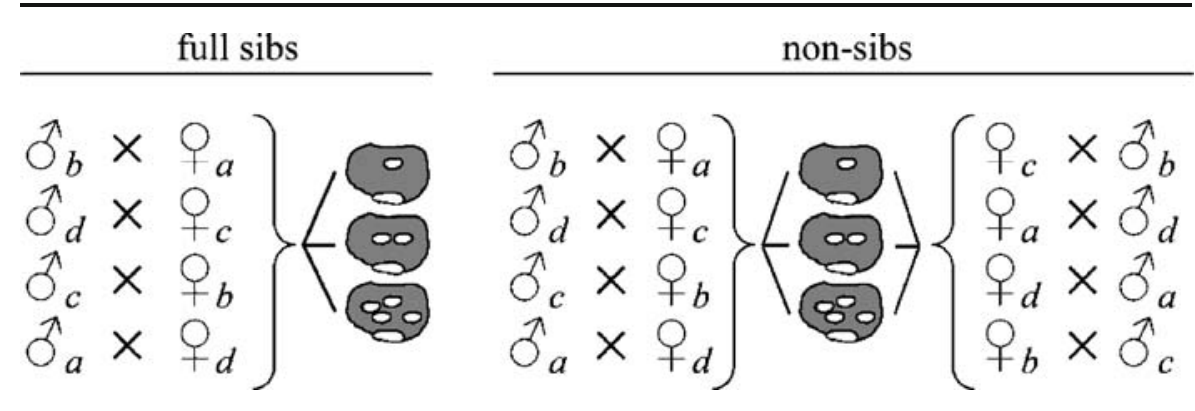

Fig. 1 Scheme of one replicate block. Each block consisted of four focal families ('a', 'b', 'c' and 'd' from the second generation of beetles) from which mating pairs were formed. Different females from each focal family were allowed to oviposit one, two, or four eggs on a bean. In the full-sib treatments a single female laid all the eggs, in non-sib treatments two (different) females each laid half the eggs each (apart form the single egg treatment which is equivalent to the full-sib low density treatment).

and kept at $29^{\circ} \mathrm{C}$ under constant light. The larvae and beetles of this third generation were used for analysis. Before pupation, larvae form translucent 'windows' by excavating up to the bean coat without breaking through. Once emergence windows appeared, observations were made at 24-h intervals. Within at maximum twelve hours after emergence, adults were sexed and weighed on an electro balance (Cahn, accurate to $10 \mu \mathrm{g}$ ). Results were averaged per bean for each set of beans.

We examined the following response variables: egg-to-adult survival, development time, adult mass, and difference in number of male and female beetles that emerged. For the analysis, we treated the measurements across the non-sib and fullsib treatments as repeated measures of the same female's offspring (Crowder and Hand 1990). That is, we matched beans with eggs from the full-sib and non-sib treatments into pairs of females from the same family (Fig. 1: the column of females under the full-sib treatment vs. the first column of females of the non-sib treatment), with pairs being the subjects, larval density and family block being the betweensubjects factors and relatedness the within-subjects factor. Larval density and relatedness were fixed factors, and family block and pair were random factors. The repeated measures design entailed that the effects of larval density and family block were tested on the mean response of each pair, and that the effect of relatedness and its interaction with larval density was tested on the difference in response of each pair. Trials were carried out randomly. Because we used four pairs of females within each family block (Fig. 1), the number of replicates per treatment combination summed up to 28. All response variables and residuals were screened for homoscedasticity and for Normality (using probability plots). Development times were log-transformed assuming multiplicative effects of the treatment. Egg-to-adult survival fractions were arcsine-transformed to fit the assumption of Normality.

\section{Results}

We first assessed treatment effects on the survival of larvae. Egg-to-adult survival decreased with increasing larval density (Table 1, Fig. 2), but was unaffected by the relatedness of individuals. Then we assessed treatment effects on the fitness-related 
Table 1 Analysis of the Effects of Larval Density (L), Family Block (B) and Relatedness (R) on Egg-toadult Survival, Development Time for Males and Females, Mass of Newly Emerged Males and Females, and the Difference in Number of Emerged Males and Females, Mass of Newly Emerged Males and Females, and the Difference in Number of Emerged Males and Females

\begin{tabular}{|c|c|c|c|c|c|c|c|c|c|c|}
\hline \multirow[t]{2}{*}{ Factor } & \multirow[b]{2}{*}{ Df } & \multicolumn{3}{|c|}{$\begin{array}{l}\text { Egg-to-adult } \\
\text { survival }\end{array}$} & \multicolumn{3}{|c|}{$\begin{array}{l}\text { Male development } \\
\text { time }\end{array}$} & \multicolumn{3}{|c|}{ Female development time } \\
\hline & & MS & $\mathrm{F}$ & $\mathrm{p}$ & MS & $\mathrm{F}$ & $\mathrm{P}$ & MS & $\mathrm{F}$ & $\mathrm{P}$ \\
\hline \multicolumn{11}{|l|}{ Between pairs } \\
\hline Larval density, L & 2 & 1.941 & 35.94 & $<0.01$ & 0.027 & 6.75 & 0.01 & 0.009 & 2.25 & 0.15 \\
\hline $\mathrm{L} * \mathrm{~B}$ & 12 & 0.054 & & & 0.004 & & & 0.004 & & \\
\hline Block, B & 6 & 0.285 & 2.74 & 0.02 & 0.004 & 1.33 & 0.26 & 0.006 & 1.50 & 0.19 \\
\hline \multirow{2}{*}{\multicolumn{11}{|c|}{ Within pairs }} \\
\hline & & & & & & & & & & \\
\hline Relatedness, R & 1 & 0.009 & 0.04 & 0.85 & 0.000 & 0.05 & 0.83 & 0.000 & 0.02 & 0.89 \\
\hline $\mathrm{R} \times \mathrm{B}$ & 6 & 0.202 & & & 0.002 & & & 0.005 & & \\
\hline $\mathrm{R} \times \mathrm{L}$ & 2 & 0.099 & 1.15 & 0.35 & 0.002 & 0.50 & 0.62 & 0.007 & 1.75 & 0.22 \\
\hline $\mathrm{R} \times \mathrm{L} \times \mathrm{B}$ & 12 & 0.086 & & & 0.004 & & & 0.004 & & \\
\hline \multirow[t]{2}{*}{ Residual } & 63 & 0.071 & & & 0.004 & & & 0.002 & & \\
\hline & & \multicolumn{3}{|c|}{ Male mass } & \multicolumn{3}{|c|}{ Female mass } & \multicolumn{3}{|c|}{$\begin{array}{l}\text { Difference in number of males } \\
\text { and females }\end{array}$} \\
\hline \multicolumn{11}{|l|}{ Between pairs } \\
\hline Larval density, L & 2 & 0.170 & 0.81 & 0.47 & 2.326 & 4.67 & $\mathbf{0 . 0 3}$ & 21.215 & 1.73 & 0.22 \\
\hline $\mathrm{L} \times \mathrm{B}$ & 12 & 0.209 & & & 0.498 & & & 12.236 & & \\
\hline Block, B & 6 & 6.594 & 36.23 & $<0.01$ & 21.280 & 37.53 & $<0.01$ & 11.552 & 2.02 & 0.08 \\
\hline $\mathrm{P}(\mathrm{L} \times \mathrm{B})$ & 63 & 0.182 & & & 0.567 & & & 5.718 & & \\
\hline \multicolumn{11}{|l|}{ Within pairs } \\
\hline Relatedness, R & 1 & 0.003 & 0.02 & 0.89 & 0.313 & 0.35 & 0.58 & 20.024 & 4.57 & 0.08 \\
\hline $\mathrm{R} \times \mathrm{B}$ & 6 & 0.178 & & & 0.907 & & & 4.385 & & \\
\hline $\mathrm{R} \times \mathrm{L}$ & 2 & 0.481 & 2.80 & 0.10 & 1.018 & 1.15 & 0.35 & 24.720 & 1.19 & 0.34 \\
\hline $\mathrm{R} \times \mathrm{L} \times \mathrm{B}$ & 12 & 0.172 & & & 0.883 & & & 20.706 & & \\
\hline Residual & 63 & 0.170 & & & 0.537 & & & 7.615 & & \\
\hline
\end{tabular}

In bold are $p$ values lower than 0.05 . Sixteen missing values occurred, because from some beans only males or females emerged in which case the development time and mass of the other sex could not be scored. Missing values were replaced with the most conservative value, i.e. the mean from corresponding cells across all treatments. The error term for Larval density as determined from the expected mean squares (Montgomery 1997) is the interaction $\mathrm{L} \times \mathrm{B}$, for Block it is $\mathrm{P}(\mathrm{L} \times \mathrm{B})$, where $\mathrm{P}$ are the female pairs (or subjects), for Relatedness it is $\mathrm{R} \times \mathrm{B}$, and for $\mathrm{R} \times \mathrm{L}$ it is $\mathrm{R} \times \mathrm{L} \times \mathrm{B}$.

traits development time and emergence mass. Development time of males was unaffected by the relatedness of individuals, but decreased with increasing larval density (Table 1, Fig. 2). However, the mass of emerging males was not affected by larval density or by relatedness (Table 1). Development time of females was unaffected by the relatedness of individuals and larval density (Table 1). The mass of emerging females was not affected by the level of relatedness of individuals, but decreased with increasing larval density (Table 1, Fig. 2). The overall mean response of body size and development time to larval food shortage as mediated by an increase in competition for males and females is summarized in Fig. 3.

There was variation among families in the mass of emerged adults (Table 1; significant block effects) and previous work has found that offspring body size is correlated with female parent body size (Messina 1990; Fox and Savalli 1998). Hence we could investigate whether higher mass of female parents and thus higher mass of larvae increased mortality. When considering only the limiting treatments 
Fig. 2 Egg-to adult survival, male development time and female emergence mass as a function of larval density in a bean: low (one larva), medium (two larvae), and high (four larvae). Vertical lines are 95\% confidence intervals.
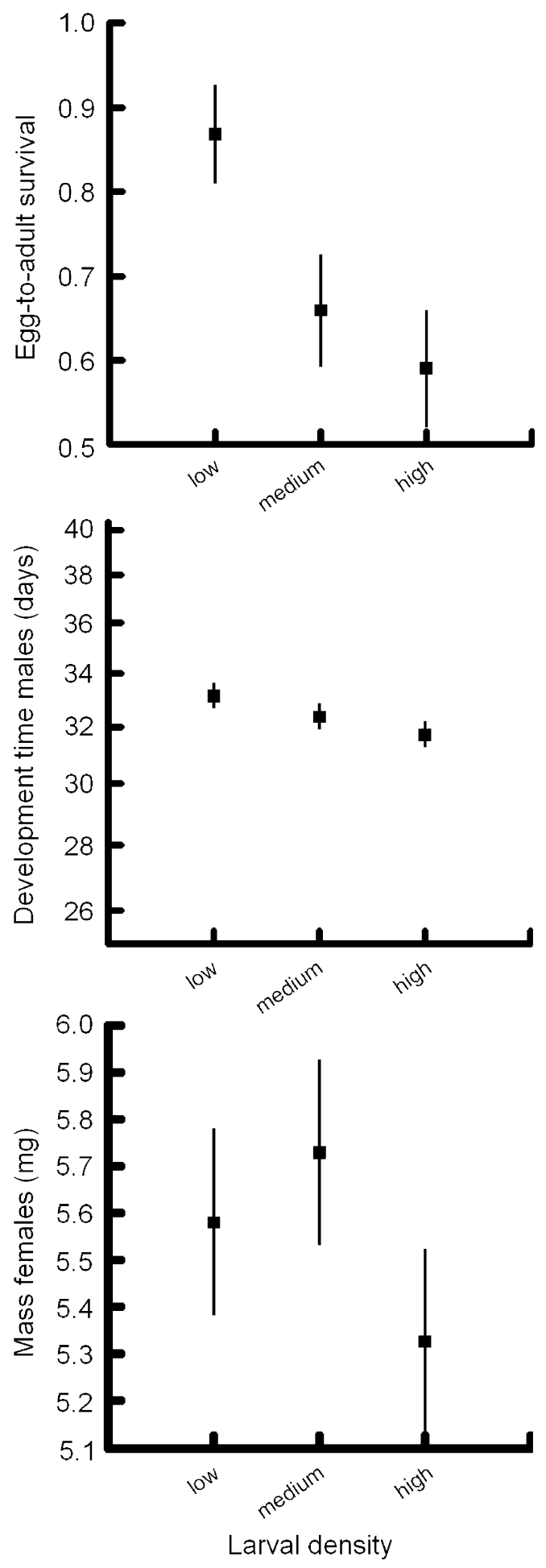
Fig. 3 Overall mean response of body size and development time to larval food shortage as mediated by an increase in competition for males and females: open symbols denote two larvae per bean; filled symbols denote four larvae per bean. Male development time significantly decreased with increasing larval density (Table 1), and female mass significantly decreased with increasing larval density (Table 1). The response of no competition (one larva per bean) was set to $100 \%$ for both males and females (square).

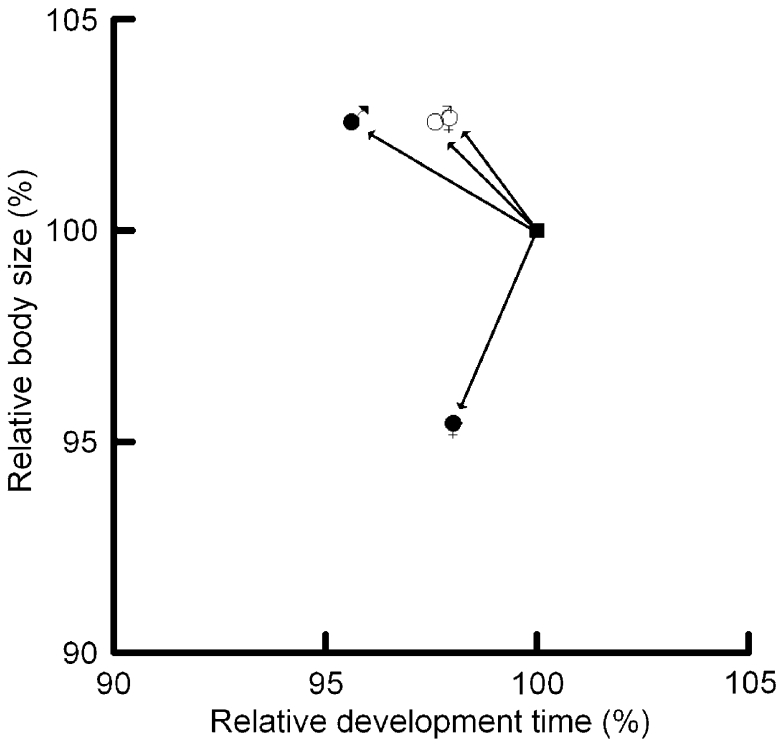

(medium and high larval densities), egg-to-adult survival (arcsine transformed) decreased with mean family adult mass as estimated from female parent mass from all larval treatments $\left(F_{1,26}=11.149, p<0.003\right)$.

\section{Discussion}

Recent work has emphasized and clarified the processes and selective forces that underlie the observation that competition between relatives can reduce or even negate the gain in inclusive fitness through the reproduction of related individuals (Queller 1994; Frank 1998, West et al. 2001; Griffin and West 2002). This process may be of importance in C. maculatus, where females tend to lay eggs in clusters (where egg density is highest in the centre of a mass of beans) even if available beans are plentiful (Stolk et al. 2001). Even though females prefer to lay a single egg on a bean (Messina and Mitchell 1989; Messina and Dickinson 1993), it is possible that due to this tendency to oviposit eggs on nearby beans (Stolk et al. 2001) cooccurrence of sibs in beans occurs in small, newly founded populations. As a result, eggs from the same female could be aggregated in both space and time and hence larvae may compete with kin. Our results support the prediction that, with such limited dispersal, an increase in competition can counteract the effect of an increase in relatedness in favoring a reduction in aggression (Queller 1994; Frank 1998). We found that $C$. maculatus larvae that competed with kin did not show a higher survival, nor were they of higher emergence mass than larvae that competed with non-kin. Our results add to the growing number of studies that fail to show a relationship between relatedness and a reduction in competition between relatives in closed systems (Walls and Blaustein 1994; Clutton-Brock et al. 2000; West et al. 2001; Pakkasmaa and Aiko 2003). Our results can be taken as evidence for the 
importance of the scale at which competition between relatives occurs, although we cannot rule out the possibility that this species has not evolved kin selected responses to within family competition, either because recognition of kin is not sufficiently reliable, or because relatives do not encounter one another sufficiently frequently, or because of other evolutionary constraints. Nevertheless, for the proposition that competition between relatives negates kin selection to be falsifiable, it is still of crucial importance to empirically show that Hamilton's rule may not hold if competition is completely local.

The second objective of our study was to assess to what extent an increase in larval density affects the survival of larvae. We observed that larval survival strongly decreased with increasing larval density. Also, larger beetles, as predicted by maternal size, were more prone to deleterious effects of competition resulting in lower survival rates, as has been shown before by Messina (2004). Competition for resources is known to affect the growth and survival of Callosobruchus beetles (Giga and Smith 1981; Credland et al. 1986; Bellows 1990; Giga and Smith 1991; Toquenaga 1993; Horng 1997; Lale and Vidal 2001; Guedes et al. 2003). In general, these studies have found that the survival of Callosobruchus larvae decreases with increasing larval density, and for contest Callosobruchus types to the extent that only one individual emerges from a bean. Yet in contrast with our work, these studies failed to control for initial larval densities (but see Messina 2004). That is, female beetles were allowed to oviposit at random, after which larval density was used as a continuous factor in the analysis, or excess eggs were scraped off beans so that larval densities would fall into one of several categories. The drawback of such an approach is that females have a choice of bean for oviposition. Beans show a wide range of physical characteristics such as size, hardness, color and texture and presumably vary substantially in their composition. All these factors have the potential to influence oviposition decisions by female $C$. maculatus and several have been demonstrated to do so (Nwanze and Horber 1976; Iloba 1985; Lale and Efeovbokhan 1991). When females preferentially lay few eggs on beans of low quality and more eggs on high quality beans, this differentially affects the strength of competition among larvae. Here, we prevented female choice by randomly assigning females to lay $x$ number of eggs per bean and by providing only a very restricted number of beans so that the strength of competition among the larvae was standardized.

Adult Callosobruchus beetles generally do not feed (Mitchell 1975), therefore resources acquired during larval development determine for a large part their size and thus longevity and reproductive potential (Messina 1993). Typically, resource limitation results in slower growth and smaller body sizes (Shorrocks 1970), which is generally predicted by life history models (Stearns 1992; Atkinson and Sibly 1997). With increasing larval density and hence limited food availability, females showed a reduction in their growth rate when food was more limited, emerging smaller after the same time. In our study, beetles were maintained on a different species of bean (the larger black-eyed bean) than those that we had used in the experiment. In a previous study, such a shift from large to smaller hosts had modified the relationship between mass and development time for females: this relationship was positive when such a host shift had not taken place, but, as in our study, non-significant when such a host shift had taken place (Messina 2004). In the 
latter study, such a host shift could have increased resource competition among larvae, but in contrast to our findings, this resulted predominantly in an increase in female development time and only in a slight increase in female mass. In contrast to the females, which are much larger than males (Bandara and Saxena 1995) and which suffered obvious negative effects of competition, the males in our study actually increased their growth rate when food became more limited, which did not compromise their adult size. Hence, as larval density increased, the adult beetles became less sexually dimorphic, a phenomenon also observed by Messina (2004).

A key assumption of many life-history models is that in ectotherms body size is proportional to development time, i.e. organisms have to grow for a longer period of time to get larger (Stearns 1992). Yet, male beetles decreased their development time, but without changing their size at maturity. Such flexibility in growth rate is advantageous in situations where growing individuals are time-limited, but where it is still advantageous to be a large (Sibly and Calow 1986; Abrams et al. 1996). This might indeed be the case for male $C$. maculatus where females inseminated by large males lay more eggs than those inseminated by small males (Savalli and Fox 1999). Also a short development time is advantageous because of the ephemeral nature of bean stores once they are infested, and because organisms with continuous generations are under constant selection to reduce generation time. The fact that males do not always maximize their growth rate suggests that costs are associated with maximizing growth rates. For instance, an individual's susceptibility to shortterm stress exerted by competition and food shortages might be increased by the higher metabolic demands that are necessary for faster growth (Gotthard et al. 1994).

Acknowledgements The authors would like to thank Bill Kunin for discussion and comments and Nick Colegrave for identifying the provenance of our beetles. IMS was supported by a PHD20 Marie Curie fellowship.

\section{References}

Abrams PA, Leimar O, Nylin S, Wiklund C (1996) The effect of flexible growth rates on optimal sizes and development times in a seasonal environment. Am Nat 147:381-395

Aerts LAM (1998) Sponge/coral interactions in Caribbean reefs: analysis of overgrowth patterns in relation to species identity and cover. Mar Ecol Prog Ser 175:241-249

Atkinson D, Sibly RM (1997) Why are animals usually bigger in colder environments? Making sense of a life history puzzle. Trends Ecol Evol 12:235-239

Bandara KAN, Saxena RC (1995) A technique for handling and sexing Callosobruchus maculatus (F.) adults (Coleoptera: Bruchidae). J Stored Prod Res 31:97-100

Bellows TS Jr (1990) Population processes and dynamics of laboratory populations of Callosobruchus spp. In: Fujii K, Gatehouse AMR, Johnson CD, Mitchel R, Yoshida T (eds) Bruchids and legumes: economics, ecology and coevolution. Kluwer, Dordrecht, pp 373-383

Clutton-Brock TH, Brotherton PNM, O’Riain MJ, Griffin AS, Gaynor D, Sharpe L, Kansky R, Manser MB, McIlrath GM (2000) Individual contributions to babysitting in a cooperative mongoose, Suricata suricatta. Proc R Soc Lond B 267:301-305

Credland PF, Dick KM, Wright AW (1986) Relationships between larval density, adult size and egg production in the cowpea seed beetle, Callosobruchus maculatus. Ecol Entomol 11:41-50

Crowder MJ, Hand DJ (1990) Analysis of repeated measures. Chapman and Hall, New York

Fellowes MDE (1998) Do non-social insects get the (kin) recognition that they deserve? Ecol Entomol 23:223-227 
Fox CW, Savalli UM (1998) Inheritance of environmental variation in body size: Superparasitism of seeds affects progeny and grandprogeny body size via a nongenetic maternal effect. Evolution 52:172-182

Frank SA (1998) Foundations of social evolution. Princeton University Press, Princeton

Giga DP, Smith RH (1981) Varietal resistance and intraspecific competition in the cowpea weevils Callosobruchus maculatus and C. chinensis (Coleoptera: bruchidae). J App Ecol 18:755-761

Giga DP, Smith RH (1991) Intraspecific competition in the bean weevils Callosobruchus Maculatus and Callosobruchus rhodesianus (Coleoptera, Bruchidae). J Appl Ecol 28:918-929

Gotthard K, Nylin S, Wiklund C (1994) Adaptive variation in growth rate: life history costs and consequences in the speckled butterfly. Oecologia 99:281-289

Grafen A (1984) Natural selection, kin selection and group selection. In: Krebs JR, Davies NB (eds) Behavioural ecology. Sinauer, Sunderland, MA, pp 62-84

Griffin AS, West SA (2002) Kin selection: fact and fiction. Trends Ecol Evol 17:15-21

Guedes RNC, Smith RH, Guedes NMP (2003) Host suitability, respiration rate and the outcome of larval competition in strains of the cowpea weevil, Callosobruchus maculatus. Physiol Entomol 28:298-305

Hamilton WD (1964a) The genetic evolution of social behavior: I. J Theor Biol 7:1-16

Hamilton WD (1964b) The genetic evolution of social behavior: II. J Theor Biol 7:17-52

Heyer WR, McDiarmid RW, Weigmann DL (1975) Tadpoles, predation, and pond habitats in the tropics. Biotropica 7:100-111

Horng SB (1997) Larval competition and egg-laying decisions by the bean weevil, Callosobruchus maculatus. Anim Behav 53:1-12

Iloba BN (1985) The cowpea seed testa and its influence on oviposition and development in Callosobruchus maculatus Fabricus (Coleoptera: Bruchidae). Niger J Plant Protect 9:11-22

Imura O (1990) Life histories of stored-product insects. In: Fujii K, Gatehouse AMR, Johnson CD, Mitchel R, Yoshida T (eds) Bruchids and legumes: economics, ecology and coevolution. Kluwer, Dordrecht, pp 257-269

Lale NES, Efeovbokhan SO (1991) Stance status of new cowpea cultivars to a storage pest, Callosobruchus maculatus. Postharvest Biol Technol 1:181-186

Lale NES, Vidal S (2001) Intraspecific and interspecific competition in Callosobruchus maculatus (F.) and Callosobruchus subinnotatus (Pic) on stored bambara groundnut, Vigna subterranea (L.) Verdcourt. J Stored Prod Res 37:329-338

Lomnicki A (1988) Population ecology of individuals. Princeton University Press, Princeton

Mano H, Toquenaga Y (2008) Wall-making behavior as a proximate mechanism to generate variation in larval competition in Callosobruchus maculatus (Coleoptera: Bruchidae). Evol Ecol 22:177-191

Messina FJ (1990) Alternative life-histories in Callosobruchus maculatus: environmental and genetic bases. In: Fujii K, Gatehouse AMR, Johnson CD, Mitchel R, Yoshida T (eds) Bruchids and legumes: economics, ecology and coevolution. Kluwer, Dordrecht, pp 303-315

Messina FJ (1993) Heritability and 'evolvability' of fitness components in Callosobruchus maculatus. Heredity 71:623-629

Messina FJ (2004) Predictable modification of body size and competitive ability following a host shift by a seed beetle. Evolution 58:2788-2797

Messina FJ, Dickinson JA (1993) Egg-laying behavior in divergent strains of the cowpea weevil (Coleoptera, bruchidae) - time budgets and transition matrices. Ann Entomol Soc Am 86:207-214

Messina FJ, Mitchell R (1989) Intraspecific variation in the egg-spacing behavior of the seed beetle Callosobruchus maculatus. J Insect Behav 2:727-742

Messina FJ, Tinney TR (1991) Discrimination between self and non-self eggs by egg-laying seed beetles a reassessment. Ecol Entomol 16:509-512

Mitchell R (1975) The evolution of oviposition tactics in the bean weevil, Callosobruchus maculatus (F.). Ecology 56:696-702

Montgomery DC (1997) Design and analysis of experiments. Wiley, New York

Newman RA (1987) Effects of density and predation on Scaphiopus couchi tadpoles in desert ponds. Oecologia 71:301-307

Nwanze KF, Horber E (1976) Seed coats of cowpea affect oviposition and larval development of Callosobruchus maculatus. Environ Entomol 5:213-218

Ofuya T, Agele S (1989) Ability of ovipositing Callosobruchus maculatus females to discriminate between seeds bearing their own eggs and those bearing eggs of other females. Ecol Entomol 14:243246

Pakkasmaa S, Aiko S (2003) Relatedness and competitive asymmetry - the growth and development of common frog tadpoles. Oikos 100:55-64

Queller DC (1994) Genetic relatedness in viscous populations. Evol Ecol 8:70-73 
Roberts WE (1994) Explosive breeding aggregations and parachuting in a neotropical frog, Agalychnis saltator (Hylidae). J Herpetol 28:193-199

Savalli UM, Fox CW (1999) The effect of male size, age, and mating behavior on sexual selection in the seed beetle Callosobruchus maculatus. Ethol Ecol Evol 11:49-60

Shorrocks B (1970) Population fluctuations in the fruit fly (Drosophila melanogaster) maintained in the laboratory. J Anim Ecol 39:229-253

Sibly RM, Calow P (1986) Physiological ecology of animals. Blackwell, Oxford

Southgate BJ (1979) Biology of the bruchidae. Annu Rev Entomol 24:449-473

Stearns SC (1992) The evolution of life histories. Oxford University Press, Oxford

Stolk C, Stein A, Slumpa SB, Tiase SK, van Huis A (2001) Exploring the foraging environment of a natural enemy of Callosobruchus maculates: Spatial egg distribution in stored cowpea. Entomol Exp Appl 101:167-181

Thornhill R, Alcock J (1983) The evolution of insect mating systems. Harvard University Press, Cambridge, MA

Toquenaga Y (1993) Contest and scramble competitions in Callosobruchus maculatus (Coleoptera: bruchidae) II. Larval competition and interference mechanisms. Res Popul Ecol 35:57-68

Toquenaga Y, Fujii K (1990) Contest and scramble competitions in Callosobruchus maculatus (Coleoptera: bruchidae) I. Larval competition curves and resource sharing patterns. Res Popul Ecol 32:199-211

Vicente VP (1990) Overgrowth activity by the encrusting sponge Chondrilla nucula on a coral reef in Puerto Rico. In: Rützler K (ed) New perspectives in sponge biology. Smithsonian Institution Press, Washington, DC, pp 436-442

Walls SC, Blaustein AR (1994) Does kinship influence density-dependence in a larval salamander? Oikos 71:459-468

West SA, Murray MG, Machado CA, Griffin AS, Herre EA (2001) Testing Hamilton's rule with competition between relatives. Nature 409:510-513

West SA, Pen I, Griffin AS (2002) Cooperation and competition between relatives. Science 296:72-75 